\title{
ANALISIS PENDAPATAN DAN NILAI TAMBAH AGROINDUTRI KERIPIK PISANG DI KECAMATAN BOJONGASIH KABUPTEN TASIKMALAYA
}

\author{
RINA APRIYANI ${ }^{1 *}$, IWAN SETIAWAN ${ }^{2}$, BUDI SETIA ${ }^{1}$ \\ ${ }^{1}$ Fakultas Pertanian Universitas Galuh \\ ${ }^{2}$ Fakultas Pertanian Universitas Padjadjaran \\ *E-mail : rinaapriyani171@gmail.com
}

\begin{abstract}
ABSTRAK
Sebagaian masyarakat bergantung pada subsektor pertanian dengan mengolah makanan dari hasil pertanian menjadi suatu produk barang jadi yang siap di makan dan di pasarkan, salah satunya keripik pisang dengan dukungan bahan baku yang tersedia. Penelitian ini bertujuan untuk mengetahui : 1. Mengetahui besarnya Biaya, Penerimaan, Pendapatan dan R/C dari pengolahan pisang menjadi keripik pisang di Kecamatan Bojongasih Kabupaten Tasikmalaya. 2. Mengetahui besarnya nilai tambah dari pengolahan pisang menjadi keripik pisang di Kecamatan Bojongasih Kabupaten Tasikmalaya. Metode yang digunakan dalam penelitian ini adalah Metode survei di Kecamatan Bojongasih Kabupaten Tasikmalaya. Data yang digunakan adalah data primer dan data sekunder. Dan sampling yang digunakan metode sensus jenuh sebanyak 2 orang. Hasil Penelitian Menunjukan bahwa :1. Rata-rata biaya total Agroindustri Keripik Pisang di Kecamatan Bojongasih Kabupaten Tasikmalaya satu kali proses produksi sebesar Rp 871,544 dan rata-rata penerimaan dalam satu kali proses produksi sebesar Rp 1.375.000 sehingga memperoleh rata-rata pendapatan sebesar Rp 503,456 dalam satu kali proses produksi dengan jumlah bahan baku sebanyak 100 kilogram dan adapun ratarata $\mathrm{R} / \mathrm{C}$ dalam satu kali proses produksi adalah 1,57 artinya usaha agroindustri keripik pisang menguntungkan dan layak untuk diusahakan. 2. Rata-rata nilai tambah dari pisang menjadi keripik pisang yang diperoleh pada Agroindustri keripik pisang di Kecamatan Bojongasih Kabupaten Tasikmalaya yaitu Rp 6,283 per kilogram dengan total produksi keripik pisang 50 kilogram dalam satu kali proses produksi.
\end{abstract}

Kata Kunci: Pendapatan, Nilai Tambah dan Agroindustri

\begin{abstract}
As a community depends on the agricultural subsector by processing food from agricultural products into a finished product that is ready to eat and market, one of them banana chips with the support of raw materials available. The research aims to know: 1. Knowing the cost, acceptance, income and $R / C$ of the processing of bananas become banana chips in the District Bojongasih Tasikmalaya Regency. 2. Know the value added from banana processing to banana chips in District Bojongasih Tasikmalaya Regency. The method used in this research is a survey method in District Bojongasih Tasikmalaya Regencyt. The data used is primary data and secondary data. And sampling used census methods are saturated as much as 2 people. The results showed that:1. The average total cost of agroindustry banana chips in District Bojongasih Tasikmalaya Regency one-time production process of RP 871,544 and average acceptance in one time production process of $R P 1,375,000$ so that the average revenue gained amounting to $R p$ 503,456 in one time production process with the amount of raw materials as much as 100 kilograms and as for the average $R / C$ in one-time production process is 1.57 means agroindustrial banana chips are profitable and worthy to be cultivated. 2 . The average value added from bananas to banana chips obtained on the banana chips Agroindustri in the district of Bojongasih Tasikmalaya regency that is Rp 6,283 per kilogram with a total production of banana chips 50 kilograms in one process production
\end{abstract}

Keywords: Income, value added and Agroindustri 


\section{PENDAHULUAN}

Yang paling besar mempunyai peran dalam pertumbuhan ekonomi negara terutama negara yang bercorak agraris seperti indonesia adalah sektor pertanian dan yang menitik beratkan pada bidang pertanian dan agroindustri bisa disebut industri yang berbasis pertanaian adalah pembangunan Ekonomi.

Untuk mendukung pembangunan pertanian dengan cara industri pengolahan hasil pertanian (pangan) adalah subsektor yang sangat penting untuk di kembangkan. Dengan di adakannya Pengembangan industri makanan diharapkan membuka kesempatan kerja dan sumber devisa serta menyediakan produk makanan yang beragam dan memberikan nilai tambah untuk produk pertanian. Maka prospek yang baik untuk masa mendatang sehingga dapat diandalkan memajukan perekonomian Indonesia adalah subsektor hortikultura. (Ibrahim, dkk, 2003 dalam Aningtyas 2011).

Di Indonesia untuk melaksanakan kegiatan pembangunan pertanian melalui tiga tahap, yaitu: 1) tahap peningkatan produktivitas, produksi dan tanaman hortikultura, tanaman perkebunan serta mutu tanaman pangan, untuk mencapai swasembada berkelanjutan. 2) tahap peningkatan nilai tambah, industri hilir, daya saing, ekspor pertanian dan pemasaran, dan 3) tahap ketahanan pangan masyarakat dan peningkatan diversifikasi. (Departemen Pertanian, 2013).

Tanaman pisang adalah salah satu komoditas hortikultura dari kelompok buah - buahan yang saat ini cukup diperhitungkan. Dengan bertambahnya jumlah penduduk dan meningkatnya kesadaran masyarakat akan pentingnya gizi dimana pisang merupakan sumber vitamin, mineral dan juga karbohidrat maka pengembangan komoditas pisang bertujuan memenuhi kebutuhan akan konsumsi buahbuahan. Menurut Bardosono (2014) Melimpahnya ketersediaan pisang menyebabkan pisang dirasakan bukanlah komoditas penting dan tidak memberikan nilai tambah bagi produsen pisang khususnya petani. Karena pisang tidak mempunyai daya simpan yang tahan lama, sehingga apabila kemelimpahannya tidak diimbangi dengan pemanfaatnya maka akan meningkatkan potensi kebusukan komoditas adalah pisang juga merupakan komoditas hortikultura, pada tahun 2013 produksi pisang di Indonesia telah mencapai 5,3 ton. Saat ini dengan pengolahan yang terbatas pisang bisa di olah menjadi jenis makanan seperti keripik, goreng pisang, sale dan kolak, selain dikonsumsi langsung sebagai buah - 
buahan. (Adriani dan Nasriati, 2011). Kecamatan Bojongasih memiliki total luas tanaman pisang yang di panen $79 \mathrm{Ha}$, lebih sempit di bandingkan dengan Kecamatan Karangjaya, Kecamataan Mangunreja dan Kecamataan Cineam. Tetapi pada rata-rata Produktivitasnya Kecamatan Bojongasih memiliki nilai Produktivitas 399,96 Kw/Ha yang lebih tingggi di bandingkan 3 Kecamatan yang memiliki areal tanaman yang lebih luas. Alasan Memilih Kecamatan Bojongasih saya ingin memanjukan Kecamatan Bojongasih agar lebih banyak memproduksi olahan pisang tersebut karena di lihat dari produksi yang di hasil cukup banyak meskipun tidak sebanyak kecamatan lainnya. Tanaman pisang dapat tumbuh di semua jenis dataran yakni dataran rendah menengah dan tinggi. Maka dari itu Kecamatan Bojongasih memanfaatkan hasil potensi tersebut untuk mengembangkan Industri rumah tangga dan Industri kecil salah satunya kegiatan pisang diolah menjadi keripik dengan adanya dukungan ketersediaan bahan baku yang tersedia di tempat serta adanya potensi pasar. Dengan di adakanya kegiatan diolahnya pisang menjadi keripik bisa mendapatkan nilai tambah lebih karena adanya biaya-biaya yang dikeluarkan sehingga menjadi produk harga baru yang lebih tinggi dan memiliki keuntungan yang cukup besar dari sebelumnya juga meningkatkan keawetan pisang hingga layak untuk di konsumsi lebih lama yang bila dibandingkan dengan produk tanpa melalui proses pengolahan, dan dengan adanya industri yang mengubah bentuk primer menjadi produk baru yang lebih tinggi nilai ekonomisnya setelah melalui proses pengolahan, maka akan mendapatkan nilai tambah dan adanya dukungan sumber daya alam, sumber daya manusia serta berperan untuk meningkatkan pendapatan tambahan bagi keluarga tani maka dari itu apakah penerimaan dan pendapatan akan menguntungkan dan Agroindustri itu layak atau tidaknya untuk di jalankan.

\section{METODE PENELITIAN}

Dalam penelitian ini, penulis menggunakan metode yang relevan pendekatan penelitian kuantitatif. Metode penelitian yang di gunakan adalah survei yang bersifat eksplorasi di Kecamatan Bojongasih Kabupaten Tasikmalaya.

\section{TEKNIK PENGUMPULAN DATA}

Data yang berhubungan dengan penelitian ini adalah:

1) Data primer adalah data yang didapatkan dan diperoleh langsung dari produsen keripik pisang.

2) Data sekunder didapatkan dari dinas yang terkait dengan penelitian dan dari 
sumber lain yaitu internet, literatur dan

berbagai buku yang berkaitan dengan

penelitian ini.

\section{TEKNIK PENARIKAN SAMPEL}

Teknik penarikan sempel untuk pengrajin dilakukan secara sensus atau sensus jenuh terhadap seluruh pengrajin keripik pisang sebanyak 2 orang dengan pertimbangan bahwa industri ini merupakan indutri yang berproduksi secara kontinyu atau berlangsung secara terus menerus.. Menurut Arikunto, (2009) sampling jenuh adalah teknik penentuan sempel bila semua anggota populasi yang digunakan sebagai sempel.

\section{Rancangan Analisis Data}

Untuk menghitung besarnya biaya, pendapatan, dan $\mathrm{R} / \mathrm{C}$, digunakan alat analisis sebagai berikut :

Biaya agroindustri keripik pisang dihitung dengan menggunakan rumus menurut Suratiyah (2006) :

$\mathrm{TC}=\mathrm{TFC}+\mathrm{TVC}$

Dimana :

$\mathrm{TC}=$ Total Cost $($ biaya total $)$
TFC = Total Fixed Cost (biaya tetap total) $\mathrm{TVC}=$ Total Variable Cost (biaya variabel total)

Untuk mengetahui penerimaan dan pendapatan digunakan rumus menurut (Soekartawi 2002) sebagai berikut :

$\mathrm{TR}=\mathrm{Y} \mathrm{x} \mathrm{Hy}$

$\mathrm{Pd}=\mathrm{TR}-\mathrm{TC}$

Dimana :

TR : Tota Revenue (Penerimaan Total (Rp))

$\mathrm{Pd}=\mathrm{TR}-\mathrm{TC}$

Dimana :

TR : Tota Revenue (Penerimaan Total (Rp))

$\mathrm{Pd}:$ Pendapataan

TC : Total Cost (Biaya Total)

Y : Jumlah produksi (Kg)

Hy : Harga Produk (Rp/Kg)

Untuk menganalisis Kelayakan Usaha Suratiyah (2006) :

$\mathrm{R} / \mathrm{C}=\frac{\text { Total Penerimaan }}{\text { Total Biaya }}$

Perhitungan dan analisis nilai tambah dalam penelitian ini menggunakan Metode Hayami dengan rumus sebagai berikut : 
Tabel 3. Format Analisis Nilai Tambah

\begin{tabular}{cll}
\hline No. & \multicolumn{1}{c}{ Variabel } & \multicolumn{1}{c}{ Nilai Simbol } \\
\hline I & Output, Input dan Harga & $(1)$ \\
1. & Hasil Produksi (Kg/proses produksi) & $(2)$ \\
2. & Bahan baku (Kg/hari) & $(3)$ \\
3. & Tenaga kerja (HOK/hari) & $(4)=(1) /(2)$ \\
4. & Faktor konversi & $(5)=(3) /(2)$ \\
5. & Koefisien tenaga kerja & $(6)$ \\
6. & Harga produk & $(7)$ \\
7. & Upah rata-rata & $(8)$ \\
II & Pendapatan dan Keuntungan & $(9)$ \\
8. & Harga bahan baku (Rp/kg) & $(10)=(4) \times(6)$ \\
9. & Nilai input lain (Rp/kg bahan baku) & $(11 \mathrm{a})=(10)-(9)-(8)$ \\
10. & Nilai Output (Rp/kg) & $(11 \mathrm{~b})=\mathrm{k}: \mathrm{j} \times 100 \%$ \\
11. & a. Nilai tambah (Rp/kg) & $(12 \mathrm{a})=(5) \times(7)$ \\
& b. Rasio nilai tambah $(\%)$ & $(12 \mathrm{~b})=(12 \mathrm{~A} / 11 \mathrm{a}) \times 100 \%$ \\
12. & a. Imbalan tenaga kerja $(\mathrm{Rp} / \mathrm{kg})$ & $(13 \mathrm{a})=(11 \mathrm{a}-12 \mathrm{a})$ \\
& b. Bagian tenaga kerja $(\%)$ & $(13 \mathrm{~b})=(13 / 11 \mathrm{a}) \times 100 \%$ \\
13. & a. Keuntungan $(\mathrm{Rp} / \mathrm{kg})$ & \\
& b. Tingkat keuntungan $(\%)$ & $(14)=(10)-(8)$ \\
III & Balas Jasa Faktor Produksi & $(14 \mathrm{a})=(12 \mathrm{a} / 14) \times 100 \%$ \\
14. & Margin (Rp/K g) & $(14 \mathrm{~b})=(9 / 14) \times 100 \%$ \\
& Pendapatan Tenaga Kerja $(\%)$ & $(14 \mathrm{c})=(13 \mathrm{a} / 14) \times 100 \%$ \\
& Sumbangan Input Lain $(\%)$ &
\end{tabular}

Sumber : Hayami dalam Maulidah, 2012

\section{HASIL DAN PEMBAHASAN}

\section{Identitas Responden}

\section{Umur responden}

Kemampuan seseorang dalam bekerja dilihat dari umur, umur merupakan faktor yang dapat mempengaruhi. Sebagian besar responden masih tergolong kedalam usia produktif, yaitu usia 50-64 tahun sehingga mempunyai tingkat kemampuan yang memungkinkan untuk menjalankan usahanya.

\section{Pendidikan responden}

Dalam kegiatan usaha tingkat pendidikan sangat penting perannya, karena dapat mempengaruhi seseorang dalam meaksanakan hal-hal baru. Pendidikan formal responden yaitu sampai Sekolah Dasar (SD). Responden mampu melaksanakan sekolah 6 tahun bahwa tingkat pendidikan responden relatif rendah karena tidak mampu melaksanakan wajib belajar 9 tahun.

\section{Jumlah Tanggungan Keluarga}

\section{Responden}

Tanggungan keluarga banyaknya jumlah anggota keluarga yang menjadi tanggungan responden untuk memenuhi kebutuhan sehari-harinya. Pada umumnya responden memiliki tanggungan keluarga 2-4 orang.

\section{Pengalaman Usaha Responden}

Pengalaman responden dalam 
mengusahakan keripik pisang yaitu 20-30 tahun. Dilihat dari pengalaman bahwa responden sudah sangat berpengalaman dalam menjalankan usahanya. Dan Pengalaman berusaha akan mempengaruhi dalam menjalankan usahanya seperti menyikapi mengambil keputusan dan menyikapi masalah dalam proses produksi keripik pisang.

\section{Analisis Biaya, Penerimaan, Pendapatan}

\section{dan R/C (Kelayakan) dan Nilai Tambah}

Biaya yang dikeluarkan oleh pengusaha keripik pisang di Kecamatan Bojongasih Kabupaten Tasikmalaya meliputi biaya tetap Tabel. 10-11 Rata-Rata Biaya,Penerimaan Agroindustri Keripik Pisang

\begin{tabular}{|c|c|c|}
\hline No. & Uraian & Jumlah (Rp) \\
\hline \multirow{3}{*}{1} & Biaya Tetap & Rp 123.650 \\
\hline & Biaya Variabel & Rp 730.500 \\
\hline & Biaya Total & $\operatorname{Rp} 854.150$ \\
\hline \multirow{3}{*}{2} & Biaya Tetap & Rp 176.315 \\
\hline & Biaya Variabel & Rp 704.000 \\
\hline & Biaya Total & Rp 888.938 \\
\hline \multicolumn{2}{|c|}{ Rata-Rata Biaya Tetap } & Rp 854.150 \\
\hline \multicolumn{2}{|c|}{ Rata-Rata Biaya Variabel } & Rp 888.938 \\
\hline
\end{tabular}

\begin{tabular}{|c|c|c|c|}
\hline \multicolumn{3}{|c|}{ Rata-Rata Biaya Total } & \multirow{2}{*}{$\begin{array}{c}\text { Rp } 871.544 \\
\begin{array}{c}\text { Penerimaan } \\
\text { Total }\end{array}\end{array}$} \\
\hline No. & Jumlah & Harga & \\
\hline 1 & 50 & $\operatorname{Rp} 25.000$ & $\operatorname{Rp} 1,250.000$ \\
\hline 2 & 50 & Rp 30.000 & Rp $1,500.000$ \\
\hline \multicolumn{3}{|c|}{ Rata-rata } & 1.375 .000 \\
\hline
\end{tabular}

Data Primer Yang Diolah 2020

Tabel 10-11 menunjukan bahwa responden keripik pisang mengeluarkan biaya tetap rata- rata sebesar Rp 146.794 dan untuk mengeluarkan biaya variabel rata-rata sebesar $\mathrm{Rp} 724,750$ dalam satu kali produksi sehingga total biaya yang dikeluarkan agroindustri tersebut adalah dan biaya variabel. Biaya tetap yang terdiri dari pajak bumi, bangunan dan penyusutan alat serta bunga modal tetap. Sedangkan biaya tidak tetap (biaya variabel) yang terdiri dari biaya (sarana produksi) penyediaan bahan baku, tenaga kerja dan transportasi. Biaya total merupakan penjumlahan antara biaya tetap dengan biaya variabel. Biaya total per satu kali proses produksi pada agroindustri keripik pisang di Kecamatan Bojongasih Kabupaten Tasikmalaya dengan rata-rata $\mathrm{Rp}$ 871.544. Untuk lebih jelasnya dapat dilihat pada Tabel dibawah. 
jumlah produk yang dihasilkan sebanyak 50 kilogram persatu kali proses produksi dari 2 responden penerimaanya berbeda karena dengan keadaan di beda desa kendala jalan yang kurang bangus mengakibatkan harga produk menjadi kurang baik, sehingga penerimaan dari penjualan keripik pisang selama satu kali proses produksi rata-rata sebesar $\mathrm{Rp}$ 1.375.000.

\section{Tabel 12. Rata-Rata Pendapan}

R/C Agroindustri Keripik Pisang

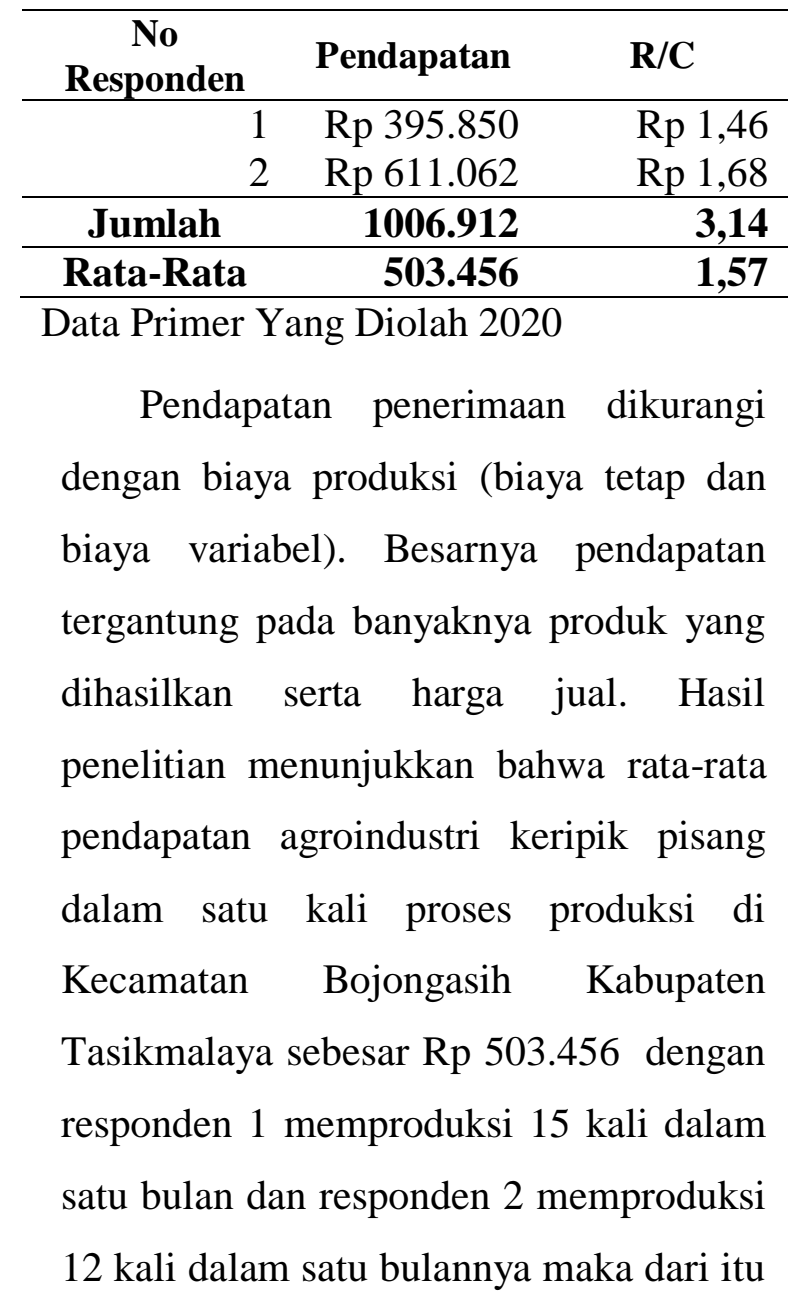

responden 2 lebih besar pendapatanya karena dengan harga produk yang di jual lebih tinggi dengan keadaan daerah yang mendukung.

$\mathrm{R} / \mathrm{C}$ digunakan untuk mengetahui layak atau tidaknya usaha agroindustri keripik pisang di Kecamatan Bojongasih Kabupaten Taiskmalaya. Rata-rata R/C agroindustri keripik pisang di Kecamatan Bojongasih Kabupaten Tasikmalaya sebesar 1,56. Artinya nilai R/C lebih besar daripada 1, maka dapat disimpulkan bahwa agroindustri Keripik layak untuk diusahakan dan menguntungkan.

\section{A. Perhitungan Nilai Tambah}

Nilai Tambah merupakan hasil olahan pertanian. Untuk menghitung nilai tambah Pisang menjadi Keripik Pisang tersebut menggunakan Metode (Hayami dalam Maulidah, 2012.

Berdasarkan hasil perhitungan menggunakan metode hayami jumlah ratarata nilai tambah yang di dapatkan responden di Kecamatan Bojongasih Kabupaten Tasikmalaya sebesar Rp 12.566 sehingga besarnya rata-rata nilai tambah agroindustri keripik pisang di Kecamatan Bojongasih Kabupaten Tasikmalaya sebesar Rp 6.283. Bisa di lihat di Tabel dibawah. 
Tabel 13. Responden 1 Nilai Tambah Keripik Pisang dalam Satu Kali Proses Produksi

\begin{tabular}{|c|c|c|}
\hline No. & Variabel & Keterangan \\
\hline 1. & Output/Total Produksi (kg) & $50 / \mathrm{Kg}$ \\
\hline 2. & Input Bahan Baku (kg) & $100 / \mathrm{Kg}$ \\
\hline 3. & Input Tenaga Kerja (HOK) & $5 / \mathrm{HOK}$ \\
\hline 4. & Faktor Konversi & 0,5 \\
\hline 5. & Koefisien Tenaga Kerja & 0,05 \\
\hline 6. & Harga Output (Rp/kg) & 25.000 \\
\hline 7. & Upah Tenaga Kerja (Rp/HOK) & 20.000 \\
\hline $\begin{array}{l}\text { II. } \\
8 .\end{array}$ & $\begin{array}{l}\text { Pendapatan dan Keuntungan } \\
\text { Harga Input Bahan Baku (Rp/kg) }\end{array}$ & $3.000 / \mathrm{Kg}$ \\
\hline 9. & Sumbangan Input Lain $(\mathrm{Rp} / \mathrm{kg})$ & $4.627 / \mathrm{Kg}$ \\
\hline 10. & Nilai Produk $(\mathrm{Rp} / \mathrm{kg})$ & $12.500 / \mathrm{Kg}$ \\
\hline 11. & $\begin{array}{l}\text { a. Nilai Tambah }(\mathrm{Rp} / \mathrm{kg}) \\
\text { b. Rasio Nilai Tambah }(\%)\end{array}$ & $\begin{array}{l}4.873 / \mathrm{Kg} \\
38,98 \%\end{array}$ \\
\hline 12. & a. Pendapatan Tenaga Kerja (Rp) & 1.000 \\
\hline & b. Bagian Tenaga Kerja (dari nilai tambah) $(\%)$ & $20,52 \%$ \\
\hline & c. Bagian Tenaga Kerja (dari produk) $(\%)$ & 3.873 \\
\hline 13. & $\begin{array}{l}\text { a. Keuntungan }(\mathrm{Rp} / \mathrm{kg}) \\
\text { b. Tingkat Keuntungan (dari nilai tambah) }(\%) \\
\text { c. Tingkat Keuntungan (dari nilai produk) }(\%)\end{array}$ & $\begin{array}{l}79,47 \% \\
9.500 / \mathrm{Kg} \\
10,52 \%\end{array}$ \\
\hline III. & Balas Jasa Pemilik Faktor Produksi & \\
\hline 14. & Marjin $(\mathrm{Rp} / \mathrm{kg})$ & $48,70 \%$ \\
\hline & a. Pendapatan Tenaga Kerja & $40,76 \%$ \\
\hline & b. Sumbangan Input Lain & $50 / \mathrm{Kg}$ \\
\hline & c. Pendapatan Perusahaan & $100 / \mathrm{Kg}$ \\
\hline
\end{tabular}

Sumber Data Primer, Analisis Nilai Tambah Agroindustri Keripik Pisang 2020

Tabel 14. Responden 2 Nilai Tambah Keripik Pisang dalam Satu Kali Proses Produksi

\begin{tabular}{|c|c|c|}
\hline No. & Variabel & Keterangan \\
\hline 1. & Output/Total Produksi (kg) & $50 / \mathrm{Kg}$ \\
\hline 2. & Input Bahan Baku (kg) & $100 / \mathrm{Kg}$ \\
\hline 3. & Input Tenaga Kerja (HOK) & 6/HOK \\
\hline 4. & Faktor Konversi & 0,5 \\
\hline 5. & Koefisien Tenaga Kerja & 0,06 \\
\hline 6. & Harga Output (Rp/kg) & 30.000 \\
\hline 7. & Upah Tenaga Kerja (Rp/HOK) & 25.000 \\
\hline $\begin{array}{l}\text { II. } \\
8 .\end{array}$ & $\begin{array}{l}\text { Pendapatan dan Keuntungan } \\
\text { Harga Input Bahan Baku (Rp/kg) }\end{array}$ & $2.500 / \mathrm{Kg}$ \\
\hline 9. & Sumbangan Input Lain $(\mathrm{Rp} / \mathrm{kg})$ & $4,807 / \mathrm{Kg}$ \\
\hline 10. & Nilai Produk (Rp/kg) & $15.000 / \mathrm{Kg}$ \\
\hline \multirow[t]{2}{*}{11.} & a. Nilai Tambah $(\mathrm{Rp} / \mathrm{kg})$ & $7.693 / \mathrm{Kg}$ \\
\hline & b. Rasio Nilai Tambah (\%) & $51,28 \%$ \\
\hline \multirow[t]{3}{*}{12.} & a. Pendapatan Tenaga Kerja (Rp) & 1.500 \\
\hline & b. Bagian Tenaga Kerja (dari nilai tambah) (\%) & $19,49 \%$ \\
\hline & c. Bagian Tenaga Kerja (dari produk) (\%) & 6.193 \\
\hline \multirow[t]{3}{*}{13.} & a. Keuntungan (Rp/kg) & $80.50 \%$ \\
\hline & b. Tingkat Keuntungan (dari nilai tambah) (\%) & $12.000 / \mathrm{Kg}$ \\
\hline & c. Tingkat Keuntungan (dari nilai produk) (\%) & $1,25 \%$ \\
\hline III. & Balas Jasa Pemilik Faktor Produksi & \\
\hline \multirow[t]{4}{*}{14.} & Marjin (Rp/kg) & $40,05 \%$ \\
\hline & a. Pendapatan Tenaga Kerja & $51,60 \%$ \\
\hline & b. Sumbangan Input Lain & $50 / \mathrm{Kg}$ \\
\hline & c. Pendapatan Perusahaan & $100 / \mathrm{Kg}$ \\
\hline
\end{tabular}

Sumber Data Primer, Analisis Nilai Tambah Agroindustri Keripik Pisang 2020 


\section{KESIMPULAN DAN SARAN}

\section{Kesimpulan}

Berdasarkan hasil penelitian maka dapat diambil kesimpulan sebagai berikut :

1. Rata-rata biaya total agroindustri keripik pisang di Kecamatan Bojongasih Kabupaten Tasikmalaya dalam satu kali proses produksi sebesar Rp 871.544 dan rata-rata penerimaan dalam satu kali proses produksi sebesar Rp 1.375.000 sehingga memperoleh rata-rata pendapatan sebesar $\mathrm{Rp}$ 503.456 dalam satu kali proses produksi dengan jumlah bahan baku sebanyak 100 kilogram adapun rata-rata R/C dalam satu kali proses produksi adalah 1,57 artinya agroindustri keripik pisang di Kecamatan Bojongasih Kabupaten Tasikmalaya menguntungkan dan layak untuk dikembangkan.

2. Rata-rata Nilai tambah dari pisang menjadi keripik pisang yang diperoleh pada Agroindustri Keripik Pisang di Kecamatan Bojongasih Kabupaten Tasikmalaya yaitu Rp 6.283 per kilogram dengan total produksi keripik pisang 50 kilogram dalam satu kali proses produksi artinya Agroindustri tersebut layak di pertahankan.

\section{Saran}

Berdasarkan kesimpulan dan pembahasan tersebut maka disarankan hal- hal sebagai berikut :

1. Agroindustri keripik pisang di Kecamatan Bojongasih Kabupaten Tasikmalaya merupakan agroindustri yang belum memiliki ijin usaha secara resmi maka dilihat dari pendapatan yang diperoleh memberikan nilai $\mathrm{R} / \mathrm{C}$ yang cukup menguntungkan di sarankan usaha tersebut perlu dikembangkan agar agroindustri tersebut menjadi berskala besar dan bisa memiliki izin usaha secara resmi.

2. Agroindustri Keripik pisang di Kecamatan Bojongasih Kabupaten Tasikmalaya memiliki nilai tambah yang positif, sehingga disarankan mempertahankan dan meningkatkan kegiatan usahanya.

\section{DAFTAR PUSTAKA}

Adisasmita, Raharjo. 2006. Pembangunan Pedesaan dan Perkotaan. Graha ilmu. Yogyakarta.

Adriani, F. Y. dan Nasriati. 2011. Teknologi Pengolahan Tepung Pisang. Balai Pengkajian Teknologi Pertanian (BPTP), Lampung.

Departemen Pertanian. 2013. Rencana Kinerja Tahunan Kementerian Pertanian Tahun 2013. Jakarta.

Hayami, dalam Maulidah. 2012. Tabel Perhitungan Nilai Tambah. Universitas Brawijaya (UB Press). Malang.

Ibrahim, dkk. 2003. Perencanaan Pengajaran. $\quad P T$. Remaja Rosdakarya. Bandung.

Soekartawi 2002. Analisis Usahatani. Jakarta: Universitas Indonesia 
Sugiyono 2013, Metodelogi Penelitian Kuantitatif, Kualitatif Dan $R \& D$. ALFABETA. Bandung:

Suprapto, Tommy, 2011. Pengantar Ilmu.

Suprapto, Tommy, 2011. Pengantar Ilmu
Komunikasi dan Peran Manajemen dalam Komunikasi, $\quad P T$. Buku Seru. Jakarta.

Suratiyah 2006. Ilmu Usahatani. Penebar Swadaya. Jakarta. 